\title{
Equity and the Social Dimension: An Overview [Overview Paper]
}

\author{
Alex Usher
}

\section{Introduction}

\begin{abstract}
Ministers affirmed that students should participate in and influence the organisation and content of education at universities and other higher education institutions. Ministers also reaffirmed the need, recalled by students, to take account of the social dimension in the Bologna process - Prague Ministerial Communique on the Bologna Process.
\end{abstract}

The 2001 Prague Communique is usually considered as the start of Europe's commitment to what has become known as the "social dimension". It was, as can be seen from the rather vague wording of the commitment, a fairly tepid endorsement of the goal of widening participation. It was not until four years later that the Bergen actually clarified that the social dimension involved a "commitment to making quality higher education equally accessible to all, and stress the need for appropriate conditions for students so that they can complete their studies without obstacles related to their social and economic background" (Bergen Declaration 2005). Yet, even if the Prague Communique was more of a rhetorical nod to students than a commitment to an active multi-lateral agenda, it nevertheless hinted at a process which could be inclusive of students and their concerns rather than one which was simply state- or institution-focused.

The Social Dimension of education is often summed up as a commitment to "equity" in education. In general, the demand for equity in higher education means two things. First, a desire for the student body to, in some sense, "look like" (i.e. be broadly representative of) the overall population, and second, a desire for educational institutions to have practices and policies which allow non-traditional students (which in this case largely means older students) to enter universities, even if they are not transferring directly from secondary school. In this sense, the "equity" agenda has a good deal of overlap with the "lifelong learning agenda". Hence, this

\footnotetext{
A. Usher $(\square)$

Higher Education Strategy Associates, Toronto, Canada

e-mail: ausher@higheredstrategy.com

(C) The Author(s) 2015

A. Curaj et al. (eds.), The European Higher Education Area,

DOI 10.1007/978-3-319-20877-0_28
} 
excerpt from the 2007 London Communique which added substantially to the Prague and Bergen statements:

We share the societal aspiration that the student body entering, participating in and completing higher education at all levels should reflect the diversity of our populations. We reaffirm the importance of students being able to complete their studies without obstacles related to their social and economic background, while stressing the efforts $[\ldots]$ to widen participation at all levels on the basis of equal opportunity. - London Ministerial Communique on the Bologna Process, 2007.

And there, for the most part, the social dimension has stood for the past seven years. Apart from rhetorical nods here and there, not much has been done to develop this theme within Bologna. This should perhaps not come as a surprise. Nearly all of the policy tools available to policymakers to improve equity lie at the level of the nation-state and not in Brussels; moreover, few if any initiatives in equity require co-operation between nation-states in order to be effective. Under the principle of subsidiarity, there is very little reason to consider educational equity an issue which requires consideration at the European level. The best one can hope for, in effect, is that Europe arrives at a situation where countries are prepared to (a) publicly report on their progress in a regular fashion and (b) learn from one another's experiences in a systemic way.

For Europe, there are three interrelated sets of questions with respect to equity which need to be addressed.

1. What are the core indicators of equity and to what extent can/should they be common across all EU countries?

2. What strategies are likeliest to improve equity in higher education and to what extent are these policies translatable across national borders?

3. In what ways policies on Equity and the Social Dimension are advanced at the European level?

We will deal now with each of these issues in turn.

\section{(i) Equity Indicators and How to Improve Them}

The goal of the Social Dimension, as defined in the London Communique, is to ensure that higher education is "reflective of the diversity" of the population. In theory, this is simple enough; however, the lens through which diversity is measured can differ significantly from one country to another. Broadly speaking, though, we can think about equity as primarily being about four areas: socio-economic background, ethnicity, gender and disabilities. Other categories are also possible, but these are the four which are the most common across Europe.

Differential access to higher education by socio-economic background is one equity area which is conceptualized in relatively constant terms across all countries, even if there are differences in categorization and measurement. All European countries - indeed, all countries everywhere - see higher participation rates among students from higher socio-economic backgrounds than from lower one. Virtually all European countries make at least some kind of nod towards the need to be more 
inclusive of youth from poorer families, even if they conceptualize the problem of differential access in completely different ways.

The United Kingdom has a series of very sophisticated ways of looking at socio-economic background; most notably, by family income based on postal code data. By virtue of having a centralized application system, the UK is also able to keep track of changes in rates of application and admissions on an annual basis. Few other countries in the European Union have admissions set-ups which are quite as well-adapted to capturing statistics on a national basis; to the extent most countries monitor socio-demographic measures they do so by looking at parental education or occupation through occasional surveys, such as those conducted by the EUROSTUDENT network. Occasionally, one has access to better quality data when large-scale labour force or household surveys happen to be exploited for these purposes. In Poland, for example, Herbst and Rok (2011) managed to construct a participation rate by family income quintile for the entire period 1990-2010 from household survey data. But this kind of project seems to be rather rare in Europe.

Multi-ethnic countries will tend to place a lot of emphasis on measuring participation rates by ethnicity (e.g. UK) unless of course the country has a policy of not asking questions and keeping statistics about race (e.g. France). Sometimes, concerns about equity boil down to a single under-privileged ethnic group (e.g. Roma in Romania). Some countries of course have few minority ethnic groups to speak of (e.g. Poland, Portugal) and so do not measure ethnicity at all. In other countries, central governments may be understandably reluctant to measure social outcomes based on ethnicity/language because of the link to separatism and irredentism (e.g. Spain, Latvia). As a result, there is nothing resembling a common indicator on minority participation in higher education and it is genuinely difficult to see how one could be constructed.

Gender equality is an area where reporting is relatively simple, but a more complicated area in which to discern what "equity" actually means. In nearly all OECD countries, women have over the last four decades predominated over men in higher education, at least as far as undergraduate enrolments are concerned. However, because men still tend to predominate in the management and operations of higher education and indeed in society as a whole, the equity concern tends not to revolve around the relative lack of men. Instead, the equity focus on gender tends to revolve around female participation in a few fields where their enrolment rates are particularly low (typically math, computer science and engineering). Yet, while it should be relatively easy to collect and compare data on women in (for instance) STEM fields, this does not appear to be done on a regular basis.

Finally, students with disabilities are also often on the list of "equity groups", but despite some attempts to put European definitions of "disability" to work, the manner in which this group is defined (and respondents' likelihood of self-identify as disabled) can vary enormously from one country to another. Martin Unger, in a paper presented at the 2014 Bologna Process researchers' Conference in Bucharest, noted that on the basis of Euro-student surveys, the percentage of students in Bologna-zone countries with self-described "study impairments" varied from about 2 to $21 \%$. This is unlikely to be a true like-to-like comparison; rather, it is a 
reflection of differences in national cultures of perceptions of self-impairment. That is to say that what counts as a visual, auditory, mobility or learning difficulty in one country may not count as such in another, based on local custom and practice.

The trickiest aspect of having student bodies "reflect the diversity" of populations is with respect to age. Clearly, universities are not going to ever reflect societal demographics on an age-basis; even where they can and should be made more welcoming to mature learners, their primary focus will always be as youth-serving institutions, helping secondary-school leavers get the knowledge and skills needed to thrive in society and in the labour force. EU states do publish relatively consistent statistics about participation rates of students aged 25 and over; however, interpreting them is far from easy, given the patchwork way in which systems (a) offer part-time studies, (b) offer distance, blended or e-learning, (c) recognize prior learning. In addition, it needs to be recognized that very different national cultures have emerged with respect to employers' willingness to allow workers to return to school (in Scandinavia this is seen as quite natural; in south-eastern Europe much less so). All of this makes it difficult to know what represents a "good" rate of participation for mature students.

The creation of a set of core indicators to measure progress in all of these areas, as mandated by the Leuven Ministerial Communique, obviously poses a conundrum. Measures need to be not just implementable across countries with differing statistical capabilities and higher education data systems, but also be common across all countries. This creates practical difficulties because of the differences in statistical capacity and statistical concepts across member states. Participation rates by gender might be a trivially easy indicator to construct, but indicators such as ethnicity, socio-economic background and disability are all fraught with difficulties because of some quite natural differences in the way countries approach this issue.

However, it is fair to ask whether or not commonality of indicators is as important to the social dimension as it is sometimes made out to be. If the purpose of a core set of indicators is to compare one country with another as well as progress over time, then it is important to have indicators which are consistent across all jurisdictions. On the other hand, if all that is desired is to measure each country's progress over time-and in practice, this is likely all that individual national governments would ever want to measure - then the possibilities for the creation of indicators opens up enormously. Freed from the need to harmonize definitions across national borders, each country could simply pick whatever indicators make sense from its own statistical systems and report on them annually.

For instance, with respect to ethnic identity, the UK might want to measure the participation of Black and South Asian youth, Romania might wish to measure participation rates of Roma youth and ethnically homogeneous Poland might not want to measure ethnicity at all. With respect to disability, one country might measure participation rates only of youth with physical disabilities, another might measure physical and visual/aural disabilities, whereas a third might have a more all-encompassing definition which also includes various types of learning disabilities. On socio-economic strata, one country might wish to measure participation 
rates by income quintile, another by parental occupation and a third by rural versus urban participation gaps.

Such an approach would have the advantage of allowing each nation to measure progress while at the same time not making overly-facile comparison across countries in very different positions. It also has the benefit that for the most part, it could be implemented relatively quickly and with little change in national statistical systems.

\section{(ii) Strategies to Improve Equity and Their Translatability}

Strategies to widen access to higher education can essentially be broken down into three types: those that are designed to eliminate barriers in the educational pipeline prior to tertiary education (broadly, what could be called "early interventions strategies"), strategies to reserve places for under-served groups, and strategies that are designed to ease financial barriers to higher education for students who have already been declared eligible for it.

Early Interventions Strategies. In Europe, the classic program of this type is the Aim higher program which existed in the UK between 2004 and 2011 and was designed to raise awareness, aspirations and attainment amongst young people from various under-represented groups. In America, there are hundreds of pre-college Outreach programs; many of these are local initiatives but there are also the very large nationally-funded programs which are collectively known under the rubric of TRIO.

Among the various tactics used in these programs are:

- Raising awareness of the benefits of higher education among youth from low-income families, especially those where no family members have previously attended higher education

- Helping young people clarify career goals and choose appropriate paths in upper secondary schools so that they have the necessary pre-requisites to attend a higher education institute of their choice

- Using of mentors to raise career aspirations and provide social and emotional support/encouragements

- Improving study skills and providing tutorial support to lower-income youth so that their academic achievement rises to the point where they can gain entrance to and succeed in higher education.

- Assisting students in choosing between higher education providers and in making applications both to institutions and to financial aid providers

- Promise of guaranteed financial assistance if/when student attends higher education.

What all of these strategies have in common is an understanding that educational inequality sets in long before tertiary education and that this inequality is caused largely by gaps in cultural and academic capital between middle-class and lower-income families. These gaps, as we know, are deeply entrenched and affect not only attitudes and habits towards schools, but also basic cognitive skills as well (most famously, Hart and Risley (2003) showed that children from high-income 
families in the US heard nearly 30 million more words from their parents over the course of their first four years of life than children from lower-income families, with predictable effects on their relative readiness to learn once they arrived at primary school). What these early intervention programs therefore seek to do is in effect generate extra cultural and academic capital in a setting outside the home, so that students from lower socio-economic backgrounds can compete on a more equal basis with middle-class ones.

It should be noted that adoption of these kinds of strategies are dependent on their being a relatively clear and open academic path towards higher education throughout secondary school, as there is in the mostly Anglophone countries where these kinds of program are most common. Where secondary schools are more rigidly streamed from an early age (as they are for instance in Germany), these kinds of interventions are less effective because there is a structural barrier preventing lower-income students in more vocational streams from easily moving up into the Abitur stream.

A second strategy for increasing equity is the use of reserved places at university for specific societal groups. These have been deployed extensively in India (for scheduled castes) and in Brazil (for Blacks); in both cases, public and private institutions have been ordered to set aside a very large number of places for these underserved groups. Generally speaking, this approach has not been favoured in developing countries for two reasons. The first is that it is seen as politically divisive unless the number of places being set aside is very small (see Cismaru et al. 2015, which describes exactly such a program for Roma students in Romania). The second reason is that there are concerns about effectiveness; this approach more or less ignores all the insights about cultural and academic capital which underpin the early interventions strategy, and simply assumes that students from disadvantages backgrounds will be able to thrive if given a place. The result often is simply that students arrive underprepared and are hence at high risk of non-completion.

The third strategy relies on removing financial barriers to students who are admitted to higher education. Note that this strategy by definition cannot affect any educational inequality which has occurred earlier in the education pipeline. That is, it can only help those who have made it through to the point of entry. This fact is one of the key fault-lines in the debate on how to achieve the third strategy: if the student population is already skewed towards the better-off section of society because of educational inequality in primary/secondary school, to what extent do high subsidies to learners constitute a regressive use of resources?

Broadly speaking, there are two theories about the nature of financial barriers and how they act to prevent students from participating in higher education. The first is that various types of fees and costs reduce the rate of return below the point where students feel it is worth their while to go. In this situation, the only correct remedy would be to reduce net costs either through grants or lower tuition fees. The second is that various types of fees and costs create liquidity problems for students. That is, students feel that education remains a positive investment, but lack the cash-on-hand to meet the fees and costs. Here, the correct policy response would be to introduce loans in order to help students meet the short-term liquidity restraint. 
Complicating this somewhat is the fact that not all students may perceive financial barriers in the same way. For some, a rise in costs (either in terms of fees or a change in the cost of living) might create a rate of return issue, while for others it might only cause a liquidity issue. In which case, does it make more sense for governments to offset rising costs with loans or grants? Clearly, there are some efficiency arguments which come into play here, and the proportion of students who view it each way is not irrelevant to determining the correct policy; unfortunately, few if any countries bother to investigate this kind of question before formulating policy.

Before examining what the evidence tells us about policy and equity, it is worthwhile reviewing some of the difficulties that exist in terms of being able to make definitive statements about "what works". There are four major problems when it comes to discovering "what works" in terms of equity in higher education. The first is the ability to collect adequate data, the second is the ability to properly attribute cause and effect, the third is the generalizability of particular results and the fourth is a tendency to re-define the term "equity" when results become inconvenient.

To begin with the problem of data: despite the rhetorical significance governments lay on equity in higher education, very few countries systematically collect data annually on any key equity criteria apart from gender. Not all countries in the European Union systematically collect data on the socio-economic backgrounds of students and when they do it is often simply to record parental occupation, which without corresponding information on occupational structure in the economy as a whole is not very useful in calculating participation rates. Data on ethnicity — at least in countries which have substantial minority ethnic populations - is also absent more often than not. Data on completion rates is available only in a minority of EU countries, and of these fewer than a half-dozen provide completion-rates data on sub-populations such as socio-economic backgrounds (European Commission/ EACEA/Eurydice 2014). As a result, when policy changes are made which might affect equity, there is little evidentiary basis on which to evaluate reforms. Where high-quality policy evaluation has been done (e.g. the work of Nielsen or Baumgartner and Steiner), it has tended to come through datasets entirely unrelated to education.

This problem of good national data is, it should be noted, of significantly more importance in Europe than it is in other parts of the world. In North America, where there is considerably more policy variation within states (because of the federal nature of both Canada and the United States) and across institutions (because of wider limits on institutional autonomy), deficiencies of national datasets can be made up through local surveys. In Europe, where national policies tend to be more uniform and policy entrepreneurialism at the institutional level is rarer, the policy "experiments" which one might want to evaluate can often only be looked at through national-level data.

The issue of cause and effect is somewhat more difficult. Equity-affecting policy decisions are rarely taken in a vacuum, and isolating the effects of one particular policy can be difficult. A similar example would be where a government in dire 
financial straits both cut public financing to universities and imposed a tuition fee increase (for example, in Canada during the latter half of the 1990s or Spain during the post-2008 austerity period). In such a situation, if one were to find a diminution of equity (e.g. a fall in the number of low-income students), it might be impossible to determine the cause. Did equity fall because tuition increased? Or did equity fall because cash-strapped institutions admitted fewer students and in so doing unwittingly push out more low-income students? Without direct access to application files - which in many places would be quite difficult to arrange - this would be a difficult question to answer. National-level indicators are very difficult to interpret in this respect; ample micro-data sets are also required in order to look at the policy effects in detail.

Occasionally, variations in policy within a state can provide valuable evidence about what works in equity. Data from the University and College Application Service in England shows that in that country, participation rates for students from lower-income backgrounds have been rising steadily for over a decade now and that the key years of 2006 (the year in which tuition rose from 1000 to 3000 GBP) and 2012 (when it rose again to $9000 \mathrm{GBP}$ ) do not show much deviation from this trend. On the surface, this might seem to be grounds for saying that rises in fees do not affect equity in participation; however, one might with reason argue that perhaps participation rates would have risen faster if tuition had not risen. This is a fair point; however, one could easily check this by looking at changes over time in low-income student participation rates in neighbouring Wales (where the English system of 2006 was adopted but not the 2012 system) and Scotland (where tuition remains free). These three countries share many educational data systems (including applications data), and share a great deal in common in terms of economics and educational structures; variations in policy between the three countries can therefore easily be exploited as a form of natural experiment. In this particular case, it turns out that participation by low-income students did not rise any faster in Scotland or Wales over this period than it did in England; moreover, the overall rate of low-income student participation is substantially higher in high-fee England than it is in no-fee Scotland.

Another possible strategy for trying to work out effects of equity policies is to compare international cases; for example: do countries with zero tuition do better at attracting low-income students than those with tuition? But this strategy is quite problematic. In our England/Scotland/Wales example, the countries shared a system with respect to measurement of participation by underserved groups; such a situation is rarely possible in other international comparisons. Also, when trying to make international comparisons all sorts of institutional differences make understanding the vectors by which equity might be affected by different sets of national policies very difficult.

Beyond the issue of identifying the effects of specific policies is the larger issue of determining whether or not such a policy would have similar effects in a different institutional setting. Many policies which look attractive and produce strong results in one place may not work very well elsewhere. For example, small, targeted programs of student grants programs might be more effective in countries where 
they are complemented by a generous loan system (e.g., the UK) than in a country where loans are non-existent (e.g. Romania). This is of course to some degree a matter of trial and error, but it underlines the need for research to not only identify "what works", but "why it works".

A final point of note here is that the definition of "what works" is much less fixed than it seems. Superficially, one might think it simply meant any policy which is consistent with higher rates of participation or completion for students from under-represented groups. But when results are politically unwelcome, one frequently finds that the definition of "what works" changes. For instance, to take the example of minority ethnic groups in the UK, student campaigners tend not to applaud the fact that Black and Asian participation rates are up; rather, the fact that these students will begin their working life with considerable debt is evidence of inequity, as it may limit their choice of career or place of residence. Such restrictions on graduates are of course valid policy concerns, but they stretch the definition of equity considerably.

With those caveats out of the way, we can look specifically at the kinds of programs which have a positive track record in terms of improving equity. With respect to early intervention programs targeted on under-represented groups, at a very general level, observers have noted that the most successful programs are the ones which (among other things) are highly intrusive (i.e. require frequent contact with young people), set high academic expectations, and empower students and parents and help them believe that they can succeed (Swail et al. 2012). In general, the programs which are most successful seem to be the more intensive ones, which combine some elements of academic support, mentoring and promises of financial support. Interventions which only attack a single one of those areas are less likely to promote access, though it is possible they may be more cost effective. One widely-noted randomized field experiment (Bettinger et al. 2012) involved offering low-income parents a chance to have their child's financial aid form filled out by a tax professional and to receive information on both tuition at nearby schools and their children's likely aid package. The result was an $8 \%$ increase in college enrolment rates among the treatment group compared to the control group.

With respect to reserving places for under-represented groups, the evidence from India and Brazil is that this system does increase access for under-represented groups in a brute-force kind of way (Carnoy et al. 2013), but there has been little follow-up with respect to subsequent success for these groups. However, as the example of the former socialist countries in Europe can attest, large-scale reservation of places for universities based on social background is a recipe for breeding cynicism about the quality of higher education.

With respect to financial interventions, there is a fair bit of research from the United States which looks at student price-response (Dynarski 2003; Heller 1997; McPherson and Schapiro 1991; Leslie and Brinkman 1987) — that is, at the overall elasticity of demand-some of which also looks specifically at student price-response among underserved groups (mainly lower-income students. Broadly speaking, the American research says that a change in net cost of $\$ 1000$ increases enrolment by 3-5\% points and that elasticity of demand is greater among students 
from lower-income backgrounds. In part because of the significant overlap between issues of class and race in the US, it is generally accepted that African American students (and to a lesser degree Latino ones) are likely to be more sensitive to changes in net price than the white students (St. John et al. 2005).

However, evidence from Europe has been more equivocal. Dearden et al. (2014), on the basis of a 2004 policy reform in the UK, calculates that a $£ 1000$ increase in maintenance grants results in a $3.95 \%$ increase in participation rates among lower-income Britons (eligibility was restricted to those with under $£ 22,500 /$ p.a. in family income). Neilsen et al. (2008) use a Danish late-1980s student aid reform which mainly benefitted upper-income students to show that a $\$ 1000$ change in aid increases participation rates by a little over $1 \%$ (it was hypothesized that the smaller price response effect in Denmark was due to the fact that costs were lower to begin with). Baumgartner and Steiner (2006), applying similar techniques to a 2001 improvement in the German Bafog system, found insignificant effects of a change in costs.

Elsewhere in the world, regular rises in fees in Australia have not stopped the number of Aboriginal students in universities increasing tenfold; similarly, the introduction of fees in New Zealand in the early 1990s did not prevent a massive increase in Maori enrolment rates. Application and enrolment rates of Blacks and Asians in the UK actually rose after both the 2006 and 2012 fee hikes, and preliminary evidence after the 2012 fee hike showed that among traditional-aged students, the rise in fees of almost $€ 7000$ per year had no effect on participation rates from young people from the poorest income quintile. Where fee rises have tended to show some significant negative impacts - particularly in England and to a lesser extent Canada - is among older students (i.e. lifelong learners) (Orr et al. 2014). Wherever data is available that allows us to look at the effects of fee increases on older students, the results seem to be the ones predicted by Human Capital Theory (Becker 1964); namely, that older students tend to be more price-sensitive than younger students, both because they have less time in which to earn back their investment and because their opportunity costs tend to be higher than for 18-19 year-olds.

The role of student loans in promoting equity is a more complicated area to study. Most American studies actually do not deal with this question directly because (i) the fact that loans are at the base of the system makes it difficult to generate useful counterfactuals through natural experiments and (ii) multivariate analysis is difficult to conduct because the amount of loans a student has almost always correlates directly with other observable characteristics (e.g. family income), which means loan amounts can never be considered fully exogenous to a model (Day 2008). There are several European countries (e.g. Sweden, Norway, The Netherlands) where loans are delivered in a way where they are not necessarily co-variate with need, but no studies on the effects of loans have been conducted there.

Arguments are frequently made with respect to the fact that loans create debt, and debt dissuades students from attending through debt aversion; the argument is also frequently made that debt aversion is disproportionately high among 
underserved youth (Orfield 1992). However, empirically this has proven difficult to sustain because it is difficult to determine for certain why students choose not to do something (in this case, borrowing). Only three studies exist which have proven the existence of debt aversion in experimental fashion. Two of these (Caetano et al. 2011; Field 2009) asked students to choose between two types of assistance which were identical in value but which were framed in such a way as to make one option seem more likely to lead to indebtedness (e.g. offering students a loan vs. offering them a "human capital contract") and found students somewhat more likely to prefer the "non-loan" option. In the third (Johnson and Montmarquette 2011), an economic lab experiment which offered binary choices (e.g. $\$ 400$ education loan vs. cash now, $\$ 200$ education grant vs. cash now) that were subsequently actually paid out to the student participants, respondents were found to only be very lightly biased towards grants over loans. Moreover, students from "underserved groups" (e.g. low-income, Aboriginal) were no more likely than average to display loan-aversion.

From a non-experimental perspective, there is the sheer weight of evidence from the 2012 UK fee hike. This, as has been pointed out elsewhere (Orr et al. 2014) was simply unprecedented in size - increases of an average $£ 5000$ (roughly $€ 7000$ ) per year. And yet, while this increase had significant effects on mature and part-time students, it had virtually no effect on traditional students, even among the lowest-income groups. The resilience of low-income students in the face of much higher prices was not because they suddenly had an extra $£ 5000$ in their pockets; rather, it was because under the national student loan program they were able to borrow this entire amount, with no questions asked.

Beyond simple issues of student costs and student debt, there are also larger system-design issues at play. Countries with larger student bodies also tend to have slightly more inclusive student bodies (Mateju 2004). This is presumably because smaller systems have filtering mechanisms, such as academic merit, which tend to systemically exclude underserved groups who-as we noted earlier - are often disadvantaged from very early on in the educational process, and so are disproportionately filtered out. But, in turn, increasing system size usually (outside Scandinavia, anyway) requires the introduction of new revenue sources such as tuition fees which of course are themselves thought to discourage participation. In some countries, though, it is clear that the introduction of tuition fees clearly expanded participation; in Poland and South Korea for instance, much of the vast wave of participation growth which occurred in the 1990s was only possible because of the existence of fully tuition-reliant private universities (Orr et al. 2014). Had there been no tuition, the hundreds of thousands of students who attended these schools would not have had the chance to attend higher education. Elsewhere, to the extent that participation may have been discouraged, it was a question of exchanging one form of discouragement (merit-based restrictions on access) for another (financial). And as systems grew, so too by and large did participation from underserved groups.

There is no easy summary from this analysis. It is important, obviously, to counter financial barriers. But doing so without first or simultaneously breaking 
down systemic barriers which block the poor and underserved before they finish secondary school risks spending a lot of money to send an already-privileged group of youth to higher education. In Scandinavia, low levels of income inequality and high levels of spending on higher education have led to highly equitable outcomes. But other countries have managed similar outcomes more cheaply (to the taxpayer, if not the student) with a mix of tuition, loans and grants.

The correct mix of policies is unlikely to be the same everywhere. Student loans have been very successful at promoting wider access in some countries, but they are likely to be problematic in places where the time between graduation and starting a full-time job capable of supporting loan repayment is very long (e.g. Southern Europe). Student grants can be a force for equalizing participation if they are correctly targeted and appropriately funded; where they are badly targeted and poorly funded - as in Romania (see Alexe et al. 2015) - they are as likely to reinforce inequality as reduce it. To put it more simply: context matters. And so, from the perspective of the development of the Social Dimension agenda, what is required to improve equity is not simply policy borrowing, but policy learning. Not just an understanding of "what works", but "where it works" and "why it works". In turn, this requires the development of much more evidence-based and deliberative kinds of forums involving both researchers and policy makers than have yet been created under the Bologna process.

\section{(iii) How can Equity and the Social Dimension be advanced at the European level?}

As the article by Kaiser, Maoláin and Vikmane in this volume makes clear, it is easy enough to become frustrated with the Social Dimension of the Bologna Process. Early hopes that governments might commit themselves to specific targets have been dashed. But, to be frank, some of these hopes were always somewhat far-fetched. Education is a national responsibility and there is no sign that national governments are in any way interested in ceding power or responsibility in this area. Bologna is not the European Commission; there was never any real prospect that it would carry with it mandatory attainment goals of the sort that one sees embedded in the Ex-ante conditionalities contained in the European Union's Structural and investment Funds.

There may, as noted earlier in Sect. 1 of this paper, be room for progress on common reporting on progress on equity if a slightly more relaxed attitude towards indicators is taken. Allowing each country to design its own way to measure participation or completion for various equity groups (e.g. socio-economic backgrounds, ethnicity, disabilities, gender, and mature learners) would speed up the process of arriving at workable indicators; moreover, by creating a set of indicators which could be used to examine national trends over time but which could not be used (or at least not easily used) to make comparisons between states, it would lessen the apprehensions of those countries who fear that the main outcome of reporting would be that countries with weaker records would simply be abused for poor performance. 
But at a deeper level, the likeliest route along which the Social Dimension may advance is to make it less about reporting and more about learning from peers. One possible way of doing this is the process of PL4SD country reviews, described ably in this volume by Orr and Mishra (this volume). The PL4SR process involves having an outside group of higher education experts look at how opportunities for students are structured at four key points (before entry to higher education, at entry, during studies, and exit/transition to the labour market) and produce a kind of formative evaluation about how current policies and structures might be adjusted in order to produce more favourable outcomes. More summative types of evaluations might be possible, but only after a sufficient number of such reviews have been done in order and clusters of countries in similar situations with similar opportunity structures had been identified, so that benchmarking and comparisons could be made only among countries in substantially similar circumstances. As with reporting on indicators, the fact that participation does not lead to invidious and politically damaging comparisons is key.

But PL4SR is not the only possible method of peer learning; as noted in the previous section, there is a crying need for more evidence-based and deliberative forums to understand what kinds of policies work in various circumstances. Europe is an enormous policy laboratory in which experiments are occurring all the time; it is a shame that this resource is currently not being exploited. Regular forums of national experts to discuss new initiatives in each country and their results could make an enormous contribution to our collective understanding of effective policies to promote equity. Continuation of support to Eurostudent, which provides probably the best snapshot of data on student life and the characteristics of the student body, would also be important. A modestly-funded European Observatory on Equity in Higher Education might be able to provide assistance to researchers in different countries who are working to quantify the effects of policy changes. Even providing seed funding for historical examinations of policy using existing household survey databases (for example, of the sort conducted by Herbst and Rok in Poland) would be massively beneficial. And once again, these are all examples of activities which can promote learning without necessarily inviting potentially embarrassing comparisons of national levels of achievement.

\section{Conclusion}

Over the past two Bologna Ministerial meetings, three commitments were made. The 2009 Leuven Communique promised that Ministers would "set measureable targets to widen participation of underrepresented groups in higher education, to be reached by the end of the next decade". That didn't happen. In the 2012 Bucharest Communique, ministers promised that they would "adopt national measures for widening overall access to quality higher education". Only nine member states chose to do so formally (Kaiser et al. 2015), though other ministers presumably took such action on equity as they would have done had the 
Communique never been adopted. They also promised in the Bucharest Communique to undertake the development of a system of voluntary peer learning. That they have done in the form of the PL4SR process.

There is a lesson here for campaigners for the social dimension. To the extent that Ministerial commitments on the social dimension are seen as opportunities to hold governments to account for their actions (or lack thereof), ministerial action will not be forthcoming. This is not because governments are uninterested in equity; it is simply because governments which signed on to the Bologna process did not do so in the expectation that their educational policies would be held up to continual critique. The speed with which PL4SR was embraced is instructive: to the extent that the Social Dimension can be cast as a learning exercise, or even as a form of technical assistance from which all governments can benefit, it will be embraced by governments.

Admittedly, casting the Social Dimension in this way likely means that it will be of more relevance to countries with weaker economies and less-developed higher education systems than it would be to, say, the UK or France. But this would seem to be a small price to pay given the benefits of turning the Social Dimension into an actual implementable policy theme.

Open Access This chapter is distributed under the terms of the Creative Commons Attribution Noncommercial License, which permits any noncommercial use, distribution, and reproduction in any medium, provided the original author(s) and source are credited.

\section{References}

Alexe, D., Haj, C. M., \& Murgescu, B. (2015). Struggling with social polarization: Student financial support in romania in the framework of the Bologna process.

Baumgartner, H. J., \& Steiner, V. (2006). Does More Generous Student Aid Increase Enrolment into Higher Education? Evaluating the German Student Aid Reform of 2001: IZA DP No. 2034

Becker, G. (1964). Human capital: A theoretical and empirical analysis with special reference to education. New York: National Bureau of Economic Research.

Bergen Declaration (2005). Declaration of the conference of European ministers responsible for higher education, 19-20 May, Bergen.

Bettinger, E., Terry Long, B., Oreopoulos, P., \& Sanbonmatsu, L. (2012). The role of application assistance and information in college decisions: Results from the h\&r block Fafsa experiment. Quarterly Journal of Economics, 127(3), 1205-1242.

Caetano, G., Patrinos, H., \& Palacios, M. (2011). Measuring aversion to debt: An experiment among student loan candidates. Policy Research Working Paper 5737: World Bank.

Carnoy, M., Loyalka, P., Dobryakova, M., Dossani, R., Froumin, I., \& Kunhs, K. et al. (2013). University Expansion in a Changing Global Economy: Triumph of the BRICs? Stanford: Stanford University Press.

Cismaru, D.-M., Fit, C., \& Gologan, D. (2015). Premises of inclusive access and success of Roma people in Romanian higher education future of higher education. Bologna process researchers conference FOHE-BPRC 2014, 24-26 November 2014, Bucharest, Romania: National Library. 
Day, K. (2008). The effect of financial aid on the persistence of university and college students in Canada. Toronto, ON: Educational Policy Institute, July 2008.

Dearden, L., Fitzsimons, E., \& Wyness, G. (2014). Money for nothing: Estimating the impact of student aid on participation in higher education. Economics of Education Review, 43, 66-78.

Dynarski, S. (2003). Does aid matter? Measuring the effect of student aid on college attendance and completion. American Economic Review, 93, 279-288.

European Commission/EACEA/Eurydice. (2014). Modernization of higher education in Europe: Access retention and employability 2014. Eurydice Report. Luxembourg: Publications Office of the European Union.

Field, E. (2009). Educational debt burden and career choice: Evidence from a financial aid experiment at NYU Law School. American Economic Journal: Applied Economics, 1(1), 1-21.

Hart, B., \& Risley, T. R. (2003). The early catastrophe: The 30 million word gap by age 3 . American Educator, 27(1), 4-9.

Heller, D. E. (1997). Student price response in higher education: An update to Leslie and Brinkman. Journal of Higher Education, 68(6), 624-659.

Herbst, M., \& Rok, J. (2011). Equity in an educational boom: Lessons from the expansion and marketization of tertiary schooling in Poland. Munich: University Library of Munich.

Johnson, C., \& Montmarquette, C. (2011). Loan Aversion Among Canadian High School Students: CIRANO.

Kaiser, F., Ó Maoláin, A., \& Vikmane, L. (2015). No Future for the Social Dimension?

Leslie, L. L., \& Brinkman, P. T. (1987). Student price response in higher education: The student demand studies. Journal of Higher Education, 58(2), 181-203.

Mateju, P. (2004). Tertiary education: Models of financing, opportunity and participation in an international comparative perspective. Paper presented at the CMEC-OECD-Canada Seminar on Student Financial Assistance, Quebec City.

McPherson, M. S., \& Schapiro, M. O. (1991). Does student aid affect college enrolment? New evidence on a persistent controversy. American Economic Review, 81, 309-318.

Neilsen, H. S., Sorenson, T., \& Taber, C. R. (2008). Estimating the effect of student aid on college enrolment: Evidence from a government grant policy reform.

Orfield, G. (1992). Money, equity, and college access. Harvard Educational Review, 62(3), 337372.

Orr, D., \& Mishra, S. (2015). A comprehensive approach to investigating the social dimension in European Higher Education Systems-EURSTUDENT and the PLASD Country Reviews.

Orr, D., Usher, A., \& Wespel, J. (2014). Do changes in cost-sharing have an impact on the behaviour of students and higher education institutions?. Brussels: European Commission.

St. John, E., Paulsen, M., \& Carter, D. F. (2005). Diversity, college costs and postsecondary opportunity: An Examination of the financial nexus between college choice and persistence for African Americans and Whites. The Journal of Higher Education, 76(5), 545-546.

Swail, W. S., Quinn, K., Landis, K., \& Fung, M. (2012). A blueprint for success: Case studies of successful pre-college outreach programs. Virginia Beach: author. 